\title{
Desempenho e Características da Carcaça de Vacas de Diferentes Grupos Genéticos em Pastagem Cultivada com Suplementação Energética
}

\author{
João Restle ${ }^{1}$, Fabiano Nunes $\mathrm{Vaz}^{2}$, Cledson Roso ${ }^{3}$, André Nunes de Oliveira ${ }^{4}$, Liliane \\ Cerdótes $^{5}$, Luis Fernando Glasenapp de Menezes ${ }^{5}$
}

\begin{abstract}
RESUMO - O objetivo deste trabalho foi testar diferentes níveis de suplementação energética na forma de grão de sorgo moído, para a terminação em pastagem, de vacas de descarte de diferentes genótipos Charolês $(\mathrm{C}) \mathrm{x}$ Nelore (N). Foram utilizadas trinta vacas de descarte, dos seguintes grupos genéticos: $\mathrm{C}, \mathrm{N}, 3 / 4 \mathrm{C}+1 / 4 \mathrm{~N}(\mathrm{CN})$ e 3/4 N + 1/4 C (NC), terminadas em pastagem cultivada de aveia (Avena strigosa) + azevém (Lolium multiflorum), distribuídas em três níveis de suplementação (NS): 0,$0 ; 0,4 ;$ ou $0,8 \%$ do peso vivo. No estudo do efeito de grupo genético, verificou-se que os ganhos de peso médio diário foram de 1,03; 1,06; 1,36; e 1,02 kg, respectivamente, para C, N, CN e NC. O peso final foi de 453,412, 515 e $478 \mathrm{~kg}$, citados na mesma ordem. O ganho de condição corporal (CC) durante a terminação foi maior nas vacas $\mathrm{N}$ ( 1,81 pontos) em relação as C (1,09 pontos) e CN ( 0,99 pontos), ficando as vacas NC com valor intermediário (1,42 pontos). Verificou-se que vacas $\mathrm{C}$ apresentam maior peso de carcaça, melhor conformação e área de Longissimus dorsi em relação às vacas $\mathrm{N}$, enquanto estas, apresentam maior percentagem de osso. As vacas CN mostraram carne de coloração mais clara que as NC. Os ganhos de peso médio diário foram de 0,$92 ; 1,23 ; \mathrm{e} 1,20 \mathrm{~kg}$, respectivamente, para os níveis 0,$0 ; 0,4$ e $0,8 \%$ de suplementação.
\end{abstract}

Palavras-chave: Avena strigosa, Charolês, grau de acabamento, Lolium multiflorum, Nelore, rendimento de carcaça, sorgo, vacas de descarte

\section{Performance and Carcass Characteristics of Cows of Different Genetic Groups, Submitted to Energetic Supplementation Levels on Winter Cultivated Pasture}

\begin{abstract}
The objective of this work was to evaluate different levels of enegetic supplementation, in the form of grounded sorghum for finishing of cull cows from different genotypes of Charolais $(\mathrm{C}) \mathrm{x}$ Nellore $(\mathrm{N})$, kept on cultivated pasture during the last half of the vegetative cycle. Thirty C, N, 3/4 C +1/4 N (CN) and 3/4 N +1/4 C (NC) beef cows, kept on cultivated pasture of oats $($ Avena strigosa $)+$ ryegrass (Lolium multiflorum) were allotted in three supplementation levels: .0, .4 or .8\% of live weight. In the study of the genetic group effect, it was observed that the average daily gain was $1.03,1.06,1.36$ and $1.02 \mathrm{~kg}$, respectively, for $\mathrm{C}$, N, CN and NC. Final live weigth was 453,412, 515 and $478 \mathrm{~kg}$, respectively. The gain in body condition during the finishing was higher for the $\mathrm{N}$ cows (1.81 points) than for the $\mathrm{C}$ (1.09 points) and $\mathrm{CN}$ ( .99 points), while the NC cows showed an intermediate value (1.42 points). Carcasses from $\mathrm{C}$ cows showed higher weight, better conformation and Longissimus dorsi area than from the N, while the last ones, showed higher bone percentage in the carcass. Between the crossbreds, the $\mathrm{CN}$ meat exhibited brighter color than the NC. With relation to the supplementation level, the average daily gain was $.92,1.23$ and $1.20 \mathrm{~kg}$, respectively, for $.0, .4$ and $.8 \%$.
\end{abstract}

Key Words: Avena strigosa, cull cows, Charolais, dressing percentage, fat thickness, Lolium multiflorum, Nellore, sorghum

\section{Introdução}

A pastagem cultivada de estação fria a base de aveia preta (Avena strigosa) + azevém (Lolium multiflorum) é a principal alternativa de alimentação utilizada na região Sul do País para a terminação de bovinos na entressafra. Além disso, é a cultura mais utilizada em rotação com as lavouras de soja e de milho.
Essas pastagens geralmente são utilizadas por períodos relativamente curtos, visando não interferir no ciclo das culturas de verão. Em razão disso, em muitos sistemas de produção, as vacas de descarte são as preferidas em relação aos novilhos, os quais necessitam de períodos mais longos para obterem bom acabamento, em função de serem animais ainda em crescimento. Também nessas pastagens, visando aumentar a lotação e a velocidade de ganho de peso

\footnotetext{
1 Eng.-Agr., PhD, Pesquisador do CNPq, Professor Titular do Departamento de Zootecnia - UFSM, Santa Maria - RS, CEP 97105-900. E-mail: jorestle@ccr.ufsm.br.

2 Zootecnista, MS, Consultor Progepec Cons. Associados Ltda. E.mail: fnvaz@terra.com.br

3 Eng.-Agr., MS, Consultor Progepec Cons. Associados Ltda.

${ }^{4}$ Zootecnista, Aluna do curso de Mestrado em Zootecnia/UFSM.

5 Acadêmico do curso de Zootecnia - UFSM.
} 
dos animais, vem sendo utilizada a suplementação energética, como demonstrou o trabalho de CALÇA et al. (1996), que suplementaram novilhos em pastagem cultivada com grão de milho, e verificaram ganho de peso diário superior a $1,50 \mathrm{~kg}$ na média dos diferentes níveis testados.

A digestibilidade da matéria orgânica das pastagens anuais de inverno é elevada na fase de crescimento da pastagem, declinando na metade final do ciclo das plantas (ROSO et al., 2000). Essa queda na digestibilidade causa uma redução no aporte energético para o animal, acarretando em redução no ganho de peso (ROSO e RESTLE, 2000). A redução na qualidade da pastagem tem reflexo ainda maior sobre o ganho de peso na fase final da terminação, em que a composição do ganho é representada principalmente pela deposição de gordura na carcaça.

O genótipo dos animais utilizados nas pastagens cultivadas é também uma constante dúvida entre os produtores. Em algumas regiões, os animais da raça Charolesa e suas cruzas são preferidos, já em outras, animais com maior grau de sangue Nelore têm maior aceitação pelos produtores. PEROBELLI et al. (1995) demonstraram que, embora o peso final seja mais acentuado em vacas de descarte Charolês, o rendimento de carcaça e a espessura de gordura são maiores em vacas Nelore.

O objetivo deste trabalho foi estudar o desempenho e características de carcaça de vacas de descarte de quatro grupos genéticos, suplementadas com diferentes níveis de grão de sorgo moído, em pastagem de aveia preta + azevém.

\section{Material e Métodos}

A fase pré-experimental deste trabalho foi realizada entre 27 de agosto e 09 de setembro e a fase experimental, de 10 de setembro a 25 de novembro de 1996. O trabalho foi conduzido nas dependências do Setor de Bovinocultura de Corte do Departamento de Zootecnia da Universidade Federal de Santa Maria, situada na Depressão Central do Rio Grande do Sul, numa altitude de $95 \mathrm{~m}$, latitude de $29^{\circ} 43^{\prime}$ sul e longitude $53^{\circ} 42^{\prime}$ oeste.

Foi avaliado o desempenho, a carcaça e a carne de vacas de descarte terminadas em condições de pastagem cultivada anual de inverno, composta por aveia preta + azevém na metade final do ciclo tes tratamentos de suplementação energética, na forma de grão de sorgo triturado: vacas sem suplementação, vacas com suplemento equivalente a $0,4 \%$ do peso vivo e vacas com suplemento equivalente a $0,8 \%$ do peso vivo. O grão de sorgo utilizado possuía, na matéria seca $(89,9 \%), 10,1 \%$ de proteína bruta e $86,7 \%$ de NDT.

Foram utilizadas 30 vacas, sendo nove Charolesas (C), nove Nelore $(\mathrm{N})$, seis $3 / 4 \mathrm{C}+1 / 4 \mathrm{~N}(\mathrm{CN})$ e seis $3 / 4 \mathrm{~N}+1 / 4 \mathrm{C}(\mathrm{NC})$, com peso médio inicial de $374 \mathrm{~kg}$ e idade média de cinco anos. A condição corporal (CC) média inicial dos animais foi de 2,7 pontos, classificada dentro de uma escala de 1 (muito magro) a 5 pontos (muito gordo). As vacas foram tomadas ao acaso do rebanho experimental da universidade e foram distribuídas ao acaso em três níveis de suplementação, equilibradas em função do grupo genético.

Os animais receberam sempre as mesmas condições de alimentação e manejo, sendo que na fase que antecedeu o experimento foram mantidas em campo nativo. Durante o período experimental, os animais foram mantidos na mesma área, com 9 ha de pastagem cultivada, implantada em março e utilizada a partir de maio até 26 de agosto com outras categorias de animais, sendo que ao iniciar o presente experimento predominava o azevém, já que a aveia estava finalizando o seu ciclo vegetativo. Diariamente pela manhã, as vacas que deviam receber suplementação foram separadas em seus respectivos tratamentos, permanecendo as vacas sem suplementação na pastagem. Após a suplementação, as vacas retornavam para a pastagem.

O sistema de pastejo empregado foi o contínuo com lotação variável utilizando a técnica put and take descrita por MOTT e LUCAS (1952). Se procurou manter uma massa de forragem superior a 2000 $\mathrm{kg}$ de $\mathrm{MS} / \mathrm{ha}$, para tal realizaram-se avaliações a cada 21 dias, através do corte de vinte amostras tomadas ao acaso. Por ocasião das avaliações, era retirada uma amostra composta para determinação das porcentagens de matéria seca, proteína bruta, fibra em detergente neutro e digestibilidade in vitro da matéria orgânica.

As vacas passaram por um período de adaptação de duas semanas, onde o nível de suplementação foi sendo gradativamente aumentado. As pesagens ocorreram ao início, após os 14 dias de adaptação, e posteriormente em intervalos de 21 dias, sendo que o último período foi de 13 dias, perfazendo um período total de terminação de 76 dias após a adaptação. Antes das pesagens, os animais eram submetidos a 
um jejum de sólidos de 12 horas.

Por ocasião do abate, que ocorreu conforme o fluxo normal do frigorífico, as carcaças foram identificadas, lavadas, pesadas e resfriadas a $-2^{\circ} \mathrm{C}$ por 24 horas. Decorrido esse tempo, as carcaças foram novamente pesadas e realizou-se a avaliação das medidas de desenvolvimento da carcaça e da conformação, seguindo-se uma escala de 1 a 18 pontos, onde um valor maior indica melhor conformação.

$\mathrm{Na}$ altura da $12^{\mathrm{a}}$ costela, foi realizado um corte perpendicular no músculo Longissimus dorsi, onde foram avaliadas as características cor, textura e marmoreio de carne. Nesse mesmo corte também foi medida a área de Longissimus dorsi e a espessura de gordura sobre o mesmo (MULLER, 1987).

Através da técnica descrita por HANKINS e HOWE (1946), realizou-se a estimativa da composição física da carcaça. Para determinar a percentagem dos cortes comerciais, dividiu-se a meia carcaça esquerda em dianteiro, traseiro e costilhar, e através de pesagem, calculou-se a percentagem destes em relação à meia-carcaça.

O delineamento experimental foi o inteiramente casualizado. Efetuou-se a análise de variância por meio do método dos quadrados mínimos (SAS, 1990), cujo modelo estatístico incluiu os efeitos fixos do nível de suplementação, grupo genético do animal, idade ao abate em anos e as interações entre esses efeitos. Como não houve interação significativa entre os efeitos principais, estas interações foram removidas do modelo final. Os dados foram analisados segundo o nível de suplementação por análise de regressão, a $5 \%$. Com relação aos grupos genéticos, os dados foram submetidos a análise de variância, a 5\%, e as médias que apresentaram diferença significativa foram comparadas pelo teste " $t$ ", também a $5 \%$ de probabilidade.

\section{Resultados e Discussão}

$\mathrm{Na}$ Tabela 1, encontram-se as características da pastagem. Verifica-se que a massa de forragem disponível foi de $2064 \mathrm{~kg}$ de MS/ha na média das quatro avaliações, ficando próxima ao valor estipulado inicialmente. Na última avaliação realizada entre 12/11 e 25/ 11 , houve queda acentuada na massa de forragem disponível (1445 kg/ha), o que se deve ao fato de que as espécies que compunham a pastagem encontravam-se em final de ciclo, quando a taxa de crescimento geralmente diminui. Também devido ao final do ciclo da pastagem, a média do teor de MS da massa de forragem dos quatro períodos foi alta $(35,16 \%)$.

A carga animal média por hectare foi de $1600 \mathrm{~kg}$ de peso vivo. No terceiro e quarto período de pastejo, utilizou-se uma carga animal menor, visando manter a massa de forragem próxima à estipulada inicialmente, pois já previa-se que a taxa de crescimento da pastagem diminuiria na fase final do seu ciclo, conforme observado por RESTLE et al. (1998a), nestas espécies forrageiras.

\begin{tabular}{|c|c|c|c|c|c|}
\hline \multirow{3}{*}{$\begin{array}{l}\text { Variáveis } \\
\text { Variables }\end{array}$} & \multicolumn{4}{|c|}{$\begin{array}{l}\text { Período } \\
\text { Period }\end{array}$} & \multirow{3}{*}{$\begin{array}{l}\text { Média } \\
\text { Mean }\end{array}$} \\
\hline & $10 / 09-30 / 09$ & $01 / 10-21 / 10$ & $22 / 10-11 / 11$ & $12 / 11-25 / 11$ & \\
\hline & $09 / 10-09 / 30$ & $10 / 01-10 / 21$ & $10 / 22-11 / 11$ & $11 / 12-11 / 25$ & \\
\hline Massa de forragem ( $\mathrm{kg} \mathrm{MS} / \mathrm{ha})$ & 2222 & 2302 & 2286 & 1445 & 2064 \\
\hline Forage mass (kg DM/ha) & & & & & \\
\hline \multirow{2}{*}{$\begin{array}{l}\text { Matéria seca (\%) } \\
\text { Dry matter (\%) }\end{array}$} & 18,28 & 29,51 & 44,10 & 48,75 & 35,16 \\
\hline & & & & & \\
\hline Carga animal (kg PV/ha) & 1766 & 1668 & 1461 & 1506 & 1600 \\
\hline Stocking rate (kg LW/ha) & & & & & \\
\hline \multirow{2}{*}{$\begin{array}{l}\text { Proteína bruta (\%) } \\
\text { Crude protein (\%) }\end{array}$} & 16,69 & 11,19 & 8,38 & 8,69 & 11,24 \\
\hline & & & & & \\
\hline Fibra em detergente neutro (\%) & 49,11 & 58,16 & 65,74 & 68,22 & 60,31 \\
\hline Neutral detergent fiber (\%) & & & & & \\
\hline $\operatorname{DIVMO}(\%)$ & 64,49 & 57,96 & 53,99 & 51,08 & 56,88 \\
\hline$I V M O D(\%)$ & & & & & \\
\hline
\end{tabular}


Ainda na Tabela 1, observa-se que o teor de PB foi de $16,69 \%$ em setembro, $11,19 \%$ no início de outubro, caindo para menos de $9 \%$ a partir de 22 de outubro. $\mathrm{O}$ teor de $\mathrm{PB}$ verificado no primeiro período de avaliação da pastagem está de acordo com a média verificada entre os meses de agosto e outubro (RESTLE et al., 1998a). Em relação à DIVMO, observa-se que esta também decresceu de $64,49 \%$ no primeiro, para 51,08\% no último período avaliado.

Os dados referentes ao desempenho das vacas, conforme o nível de suplementação que receberam, encontram-se na Tabela 2. Verifica-se que o peso final não foi afetado pela suplementação, embora o ganho de peso médio diário, durante os 76 dias de terminação, tenha aumentado à medida que foi incrementado o nível de suplementação utilizado, conforme a equação: $\mathrm{Y}=0,853+0,627 \mathrm{NS}(\mathrm{P}<0,02)$, em que NS é o nível de suplementação em porcentagem do peso vivo.

$\mathrm{O}$ aumento no GMD indica que ocorreu um efeito aditivo da suplementação, que pode ter sido em função do aumento no consumo alimentar (PASCOAL et al. 1999) e ou pela substituição da forragem pelo grão de sorgo, proporcionando maior aporte de energia.

Segundo MÉNDEZ et al. (1997), o pastoreio contínuo de bovinos sobre pastagem de triticale (X triticosecale) e a adição de suplemento energético não alteraram o ganho de peso dos animais. RESTLE et al. (2000d), utilizando o grão de sorgo como suplemento para vacas de descarte, nos níveis de $0 ; 0,3$;
0,6 ; e $0,9 \%$ do peso vivo, durante a terminação em pastagem de $X$ triticosecale + Lolium multiflorum sob pastejo horário, não observaram diferenças no GMD, que variou de $1,44 \mathrm{~kg}$, nas vacas suplementadas com $0,3 \%$ do peso vivo, a $1,51 \mathrm{~kg}$ nas vacas suplementadas com $0,9 \%$ do peso vivo.

Considerando-se que as vacas utilizadas por RESTLE et al. (2000d) são provenientes do mesmo rebanho experimental das utilizadas neste estudo, assim como a área experimental foi a mesma, o maior GMD verificado nas vacas utilizadas pelos autores supracitados, pode ter sido, em parte, resultado da melhor qualidade da forragem ofertada, que foi de junho a agosto, na fase de crescimento da pastagem, quando a qualidade das espécies é mais alta, enquanto que as vacas do presente trabalho, pastejaram de setembro a novembro, período de pleno florescimento das pastagens hibernais, portanto com teor de fibra mais elevado. Prova disso é que as médias de GMD foram de $1,46 \mathrm{~kg}$, de 10 a 30 de setembro, de $1,23 \mathrm{~kg}$, de $1^{\circ}$ a 21 de outubro, de $0,85 \mathrm{~kg}$, de 22 de outubro a 11 de novembro, mantendo esse mesmo GMD de 12 a 25 de novembro.

No trabalho de RESTLE et al. (2000d), as vacas não suplementadas apresentaram $1,48 \mathrm{~kg}$ de ganho de peso por dia, enquanto as vacas do presente trabalho apresentaram ganho médio diário de $0,92 \mathrm{~kg}$. A diferença no ganho de peso verificada nos dois trabalhos pode ser em função da qualidade das duas pastagens. Enquanto no presente trabalho, os valores

Tabela 2 - Peso inicial, peso final, ganho de peso médio diário, condição corporal (CC) inicial, final e ganho de CC de vacas de corte terminadas com diferentes níveis de suplementação em pastagem cultivada

Table 2 - Initial weight, final weight, average daily weight gain, initial body condition (BC), final BC and BC gain of beef cows, finished with different suplementation levels on cultivated pasture

\begin{tabular}{|c|c|c|c|c|}
\hline \multirow[t]{2}{*}{$\begin{array}{l}\text { Característica } \\
\text { Characteristic }\end{array}$} & \multicolumn{3}{|c|}{$\begin{array}{l}\text { Nível de suplementação (NS) } \\
\text { (\% do peso vivo) } \\
\text { Supplementation level } \\
(\% \text { of live weight })\end{array}$} & \multirow[t]{2}{*}{$\begin{array}{c}\text { Equação de regressão } \\
\text { Regression equation }\end{array}$} \\
\hline & 0 & 0,4 & 0,8 & \\
\hline $\begin{array}{l}\text { Peso inicial, } \mathrm{kg} \\
\text { Initial weight, } \mathrm{kg}\end{array}$ & $368+16$ & $378+16$ & $376+16$ & $Y=374$ \\
\hline $\begin{array}{l}\text { Peso final, } \mathrm{kg} \\
\text { Final weight, } \mathrm{kg}\end{array}$ & $445+18$ & $483+17$ & $485+17$ & $Y=465$ \\
\hline $\begin{array}{l}\text { Ganho médio diário, } \mathrm{kg} \\
\text { Average daily gain, } \mathrm{kg}\end{array}$ & $0,92+0,07$ & $1,23+0,07$ & $1,20+0,07$ & $\mathrm{Y}=0,853+0,627 \mathrm{NS}^{\mathrm{A}}$ \\
\hline $\begin{array}{l}\mathrm{CC} \text { inicial, pontos } \\
\text { Initial } B C \text {, points }\end{array}$ & $2,72+0,16$ & $2,85+0,16$ & $2,88+0,16$ & $Y=2,77$ \\
\hline $\begin{array}{l}\text { CC final, pontos } \\
\text { Final BC, points }\end{array}$ & $3,87+0,16$ & $4,31+0,16$ & $4,25+0,17$ & $\mathrm{Y}=4,14$ \\
\hline $\begin{array}{l}\text { Ganho de CC, pontos } \\
B C \text { gain, points }\end{array}$ & $1,15+0,15$ & $1,46+0,15$ & $1,37+0,15$ & $\mathrm{Y}=1,100+0,625 \mathrm{NS}^{\mathrm{B}}$ \\
\hline
\end{tabular}


para proteína bruta, fibra em detergente neutro e digestibilidade in vitro da matéria orgânica foram de $11,24,60,31$ e $56,88 \%$ (Tabela 1 ), respectivamente, RESTLE et al. (2000d) verificaram 20,0, 57,4 e $64,0 \%$, na mesma ordem. A diferença na composição das pastagens deve-se ao estádio vegetativo das mesmas, visto que não se deve esperar que o fato de usar azevém ou triticale em mistura com a aveia possa afetar o GMD dos animais, conforme demonstrado por ROSO (1998).

Observa-se, ainda na Tabela 2, que a CC final das vacas não alterou com o aumento do nível de suplementação $(\mathrm{P}>0,05)$. Estudando duas condições corporais, FEIJÓ et al. (2000a) verificaram que vacas com melhor condição inicial apresentaram menor ganho de peso do que vacas que iniciaram o trabalho em pior estado. Trabalhando com vacas suplementadas, RESTLE et al. (2000d) verificaram que a CC final foi de 3,$48 ; 3,56$; 3,87 ; e 3,97 pontos, respectivamente, para vacas terminadas em pastagem cultivada com suplementação equivalente a $0 ; 0,3 ; 0,6$; e $0,9 \%$ do peso vivo, conforme a seguinte equação de regressão: $\mathrm{Y}=3,365+0,633 \mathrm{NS}$ (sendo NS em percentagem do peso vivo).

A suplementação com grãos rapidamente fermentáveis, em dietas à base de forragem, pode aumentar o aporte de energia pela elevação na proporção de propionato e no total de ácidos graxos voláteis. Outros efeitos que ocorrem são o aumento da digestão intestinal do amido que escapa à degradação ruminal e o aumento do fluxo de matéria orgânica microbiana que atinge o intestino delgado.

No presente trabalho, o ganho de CC aumentou linearmente com o aumento do nível de suplementação em percentagem do peso vivo (NS), conforme a equação, $\mathrm{Y}=1,100+0,625 \mathrm{NS}\left(\mathrm{R}^{2}=0,29 ; \mathrm{P}<0,05\right)$. A melhoria da $\mathrm{CC}$ dos animais é um aspecto importante, quando se deseja obter mais rápido acabamento, possibilitando a comercialização antecipada dos animais. SCHNELL et al. (1997) comentam que a melhora de CC final é muito desejável, pois isso acarreta maior rendimento de carcaça, maciez da carne e melhor coloração da gordura.

Os resultados referentes às características de carcaça das vacas do presente trabalho são apresentados na Tabela 3. O peso de carcaça fria foi semelhante entre os três grupos de vacas estudados.

Também trabalhando com vacas de descarte, FEIJÓ et al. (2000b) verificaram que vacas não suplementadas com concentrado energético apresentaram peso médio de carcaça de $219 \mathrm{~kg}$, enquanto as

Tabela 3 - Peso de carcaça fria, rendimento de carcaça fria, conformação, espessura de gordura subcutânea, comprimento de carcaça e percentagem dos cortes comerciais da carcaça de vacas terminadas com diferentes níveis de suplementação em pastagem cultivada

Table 3 - Cold carcass weight, dressing percentage, conformation, subcutaneous fat thickness, carcass length and commercial cuts of the carcass of cows, finished with different levels of supplementation on cultivated pasture

\begin{tabular}{|c|c|c|c|c|}
\hline \multirow[t]{2}{*}{$\begin{array}{l}\text { Característica } \\
\text { Characteristic }\end{array}$} & \multicolumn{3}{|c|}{$\begin{array}{c}\text { Nível de suplementação (NS) } \\
\text { (\% do peso vivo) } \\
\text { Supplementation level } \\
\text { (\% of live weight) }\end{array}$} & \multirow[t]{2}{*}{$\begin{array}{l}\text { Equação de regressão } \\
\text { Regression equation }\end{array}$} \\
\hline & 0 & 0,4 & 0,8 & \\
\hline $\begin{array}{l}\text { Peso de carcaça fria, } \mathrm{kg} \\
\text { Cold carcass weight, } \mathrm{kg}\end{array}$ & $229,3+10,1$ & $252,3+9,1$ & $255,5+9,1$ & $\mathrm{Y}=242,8$ \\
\hline $\begin{array}{l}\text { Rendimento de carcaça, } \% \\
\text { Dressing percentage, } \%\end{array}$ & $51,5+0,9$ & $52,3+0,8$ & $52,7+0,8$ & $\mathrm{Y}=52,2$ \\
\hline $\begin{array}{l}\text { Conformação, pontos } \\
\text { Conformation, points }\end{array}$ & $8,6+0,4$ & $9,6+0,4$ & $9,2+0,4$ & $\mathrm{Y}=9,0$ \\
\hline $\begin{array}{l}\text { Espessura de gordura, } \mathrm{mm} \\
\text { Fat thickness, } \mathrm{mm}\end{array}$ & $6,1+1,0$ & $6,4+0,9$ & $7,4+0,9$ & $Y=6,6$ \\
\hline $\begin{array}{l}\text { Comprimento de carcaça, } \mathrm{cm} \\
\text { Carcass length, } \mathrm{cm}\end{array}$ & $131,1+1,6$ & $131,8+1,4$ & $132,0+1,4$ & $\mathrm{Y}=131,0$ \\
\hline $\begin{array}{l}\text { Dianteiro, } \% \\
\text { Forequarter, \% }\end{array}$ & $36,0+0,8$ & $37,1+0,7$ & $36,3+0,7$ & $Y=36,7$ \\
\hline $\begin{array}{l}\text { Costilhar, \% } \\
\text { Sidecut, \% }\end{array}$ & $12,7+0,4$ & $12,6+0,3$ & $12,1+0,3$ & $\mathrm{Y}=12,91-1,19 \mathrm{NS}^{\mathrm{A}}$ \\
\hline $\begin{array}{l}\text { Traseiro especial, \% } \\
\text { Sawcut, \% }\end{array}$ & $51,3+0,8$ & $50,2+0,7$ & $51,6+0,7$ & $\mathrm{Y}=50,9$ \\
\hline
\end{tabular}

$\mathrm{A} R^{2}=0,1254 ; \mathrm{P}=0,05\left(R^{2}=.1254 ; P=.05\right)$. 
vacas que consumiram concentrado energético nas proporções de 0,5 e 1,0\% do peso vivo, alcançaram peso de carcaça de 231 e $235 \mathrm{~kg}$, respectivamente.

Com relação ao rendimento de carcaça fria, observa-se que não houve diferença entre os três tratamentos. Ao verificarem maior rendimento de carcaça em animais alimentados com maiores níveis de concentrado, FEIJÓ et al. (1996a) atribuíram tal fato ao menor conteúdo gastrointestinal que uma dieta com menor teor de fibra propicia. Entretanto, RESTLE et al. (2000e) afirmam que esse efeito pode não ser tão evidente quando o volumoso utilizado possui rápida passagem pelo trato digestivo, como é o caso da pastagem cultivada formada pela mistura de aveia e azevém durante a fase de crescimento. Esses comentários são ratificados no trabalho de RESTLE et al. (2000b), que mostram maior rendimento em animais terminados em pastagem cultivada de aveia + azevém no sistema de pastejo horário suplementado, em relação aos terminados em confinamento com silagem de sorgo forrageiro ou de duplo propósito.

A conformação de carcaça dos animais não diferiu entre os tratamentos, sendo classificada como regular mais nas carcaças das vacas que não foram suplementadas ( 8,58 pontos) e nos animais que receberam $0,8 \%$ de suplemento $(9,16$ pontos) a boa menos (9,60 pontos) nos animais que receberam $0,4 \%$ de suplemento. Estudando novilhos $F_{1}$ Pardo Suíço $\mathrm{x}$ alimentados com níveis de concentrado nas proporções de $0 ; 0,5 ; 1,0$ e 1,5\% do peso vivo, FEIJÓ et al. (1996c), não encontraram diferença na conformação de carcaça dos animais. Trabalhando com vacas de descarte terminadas em confinamento com diferentes níveis de concentrado, RESTLE et al. (1998b) observaram que a conformação de carcaça foi de 8,$12 ; 8,50$ e 8,62 pontos, respectivamente, para vacas em confinamento, recebendo dietas com 35,50 ou $65 \%$ de concentrado.

A espessura de gordura foi de 6,12;6,44 e 7,37 mm, respectivamente, para os níveis de $0 ; 0,4$ e $0,8 \%$ de suplemento. Utilizando vacas de descarte $\mathrm{C} \times \mathrm{N}$, RESTLE et al. (1998b) observaram que a espessura de gordura foi de 3,$12 ; 3,88$ e $3,38 \mathrm{~mm}$, respectivamente, para vacas alimentadas com 35,50 e $65 \%$ de concentrado, na dieta do confinamento. FEIJÓ et al. (2000b) observaram que níveis de concentrado equivalentes a $0 ; 0,5$ e $1,0 \%$ do peso vivo resultaram em espessura de gordura semelhante, variando de 5,5 a $6,4 \mathrm{~mm}$. Trabalhando com nível de suplementação para vacas terminadas em pastejo horário sobre azevém + triticale, foi observado, que o incremento no nível de suplementação energética aumentou a espessura de gordura, resultando em regressão linear positiva (RESTLE et al., 2000e).

O comprimento de carcaça também foi similar entre os três grupos de vacas avaliados, assim como as percentagens de corte dianteiro e traseiro especial da carcaça não sofreram influência do nível de suplementação. FEIJÓ et al. (2000b) verificaram que o comprimento de carcaça das vacas não sofreu efeito do nível energético durante a terminação, mas observaram menor percentagem de traseiro especial nas vacas alimentadas com níveis mais altos de concentrado. No presente trabalho, a regressão foi linear e negativa $(\mathrm{P}<0,05)$ para percentagem de costilhar em relação ao nível de concentrado.

$\mathrm{Na}$ Tabela 4 são apresentados os resultados referentes às características qualitativas da carcaça e, observa-se, que à composição física da carcaça não foi influenciada pelos níveis de suplementação utilizados. FEIJÓ et al. (1996b) testaram os níveis de concentrado variando de 0 a $60 \%$ da dieta em confinamento, e verificaram maior percentagem de ossos no nível $40 \%$, sendo que as percentagens de músculo e gordura foram maiores no nível de $20 \%$ de concentrado.

Pode-se observar que não houve diferença nas percentagens de ossos, músculo e tecido adiposo da carcaça. Segundo BERG e BUTTERFIELD (1976), desde que o peso de abate seja semelhante, não são esperadas diferenças na composição corporal de animais que passam por crescimento compensatório durante a terminação. Quando se trabalha com terminação de vacas, espera-se que o ganho de peso seja em parte constituído por recuperação de CC, ou seja, um fenômeno que pode ser considerado como ganho de peso compensatório, pois animais adultos já possuem seu crescimento ósseo definido, ocorrendo então aumento de peso dos tecidos muscular e adiposo (DI MARCO, 1994).

$\mathrm{Na}$ Tabela 4 pode-se verificar que a coloração da carne e o marmoreio foram semelhantes entre os três níveis de suplementação testados, sendo que as vacas não suplementadas apresentaram classificação leve menos, e as vacas que receberam 0,4 e $0,8 \%$ de suplemento apresentaram marmoreio classificado como leve mais.

Trabalhando com níveis de concentrado variando de 0 a $60 \%$ na dieta de animais $\mathrm{N}$ confinados, FEIJÓ et al. (1996b) não observaram diferença significativa na cor e textura da carne, entretanto, observaram maior marmoreio na carne nos níveis mais baixos de 
Tabela 4 - Características qualitativas da carcaça e área de Longissimus dorsi (LD) de vacas de corte terminadas com diferentes níveis de suplementação em pastagem cultivada

Table 4 - Carcass quality and Longissimus dorsi (LD) area of beef cows finished with different levels of supplement on cultivated pasture

\begin{tabular}{|c|c|c|c|c|}
\hline \multirow[t]{2}{*}{$\begin{array}{l}\text { Característica } \\
\text { Characteristic }\end{array}$} & \multicolumn{3}{|c|}{$\begin{array}{c}\text { Nível de suplementação (NS) } \\
\text { (\% do peso vivo) } \\
\text { Supplementation level } \\
\text { (\% of live weight) }\end{array}$} & \multirow[t]{2}{*}{$\begin{array}{l}\text { Equação de regressão } \\
\text { Regression equation }\end{array}$} \\
\hline & 0 & 0,4 & 0,8 & \\
\hline $\begin{array}{l}\text { Osso, \% } \\
\text { Bone, \% }\end{array}$ & $16,6+0,6$ & $15,9+0,5$ & $15,6+0,5$ & $\mathrm{Y}=16,2$ \\
\hline $\begin{array}{l}\text { Músculo, \% } \\
\text { Muscle, \% }\end{array}$ & $61,5+1,0$ & $62,5+0,9$ & $60,4+0,9$ & $\mathrm{Y}=61,3$ \\
\hline $\begin{array}{l}\text { Gordura, \% } \\
\text { Fat, \% }\end{array}$ & $21,6+1,1$ & $21,6+1,0$ & $24,0+1,0$ & $\mathrm{Y}=22,4$ \\
\hline $\begin{array}{l}\text { Cor, pontos } \\
\text { Color, points }\end{array}$ & $4,7+0,2$ & $4,5+0,2$ & $4,4+0,2$ & $Y=4,5$ \\
\hline $\begin{array}{l}\text { Textura, pontos } \\
\text { Texture, points }\end{array}$ & $3,3+0,4$ & $2,7+0,4$ & $2,4+0,4$ & $\mathrm{Y}=2,8$ \\
\hline $\begin{array}{l}\text { Marmoreio, pontos } \\
\text { Marbling, points }\end{array}$ & $4,4+1,3$ & $6,1+1,2$ & $6,2+1,2$ & $Y=5,4$ \\
\hline $\begin{array}{l}\text { Área de LD, } \mathrm{cm}^{2} \\
L D \text { area, } \mathrm{cm}^{2}\end{array}$ & $55,2+2,5$ & $60,8+2,3$ & $65,1+2,3$ & $\mathrm{Y}=60,4$ \\
\hline
\end{tabular}

concentrado. Entretanto, não se verificou diferença estatística nessas três características quando esses mesmos níveis foram oferecidos para animais $\mathrm{F}_{1}$ Pardo Suiço x N, enquanto RESTLE et al. (2000c) verificaram textura mais fina na carne de animais terminados com níveis mais baixos de concentrado. A análise de regressão não mostrou diferença significativa entre tratamentos, sendo o valor médio de Longissimus dorsi de $60,4 \mathrm{~cm}^{2}$.

$\mathrm{Na}$ Tabela 5, estão apresentados os resultados referentes ao desempenho animal em função do grupo genético das vacas. O ganho de peso médio diário foi maior nas vacas $\mathrm{CN}$, em relação aos demais grupos genéticos avaliados. $\mathrm{O}$ maior ganho de peso obtido nesse grupo genético de vacas pode ser considerado como resultante do somatório do efeito genético individual aditivo da raça Charolês e da heterose materna (DeROUEN et al., 1992a), além do efeito de heterose individual nos animais 3/4 em relação aos definidos (PEACOCK et al., 1979; VAZ, 1999).

As vacas $\mathrm{CN}, \mathrm{NC}$ e $\mathrm{C}$ foram superiores às $\mathrm{N}$ quanto ao peso de abate $(\mathrm{P}=0,0353)$. Ao verificarem maior peso de abate em vacas $\mathrm{C}$ em relação às $\mathrm{N}$, PEROBELLI et al. (1995) atribuíram tal fato ao maior porte da raça continental. No presente trabalho pode-se observar que a média de peso ao abate das vacas cruzadas $(500,5 \mathrm{~kg})$ foi $13,6 \%$ superior ao da média das vacas de raças definidas $(440,5 \mathrm{~kg})$ percentual superior ao verificado por VAZ (1999), onde a média para o peso de abate de novilhos $3 / 4$ foi $10,1 \%$ superior aos animais de raças definidas.

A CC final não diferiu entre os diferentes grupos genéticos $(\mathrm{P}>0,10)$, no entanto, o ganho de $\mathrm{CC}$ foi maior nas vacas $\mathrm{N}$, quando comparadas com as vacas $C$ ou cruzadas, resultado que pode ser atribuído à pior $\mathrm{CC}$ das vacas zebuínas ao início do trabalho.

$\mathrm{Na}$ Tabela 6, são apresentados os resultados referentes às características de carcaça, em função dos grupos genéticos, das vacas. Observa-se que devido à similaridade no rendimento de carcaça, o peso de carcaça fria seguiu a mesma tendência do peso de abate (Tabela 5).

Estudando vacas de descarte da raça Charolesa e Nelore, PEROBELLI et al. (1995) verificaram maior rendimento de carcaça nas vacas de raça européia. GALVÃO et al. (1991) comentam que o maior rendimento de carcaça de animais zebuínos se deve ao menor peso relativo de cabeça, patas e couro. Em seu trabalho, VAZ (1999) complementa essa observação referindo-se ao menor arqueamento de costelas dos animais Nelore em relação aos Charolês, verificando que animais cruzados Charolês x Nelore e Nelore x Charolês podem apresentar rendimentos de carcaça comparáveis ao rendimento da raça Nelore. Ao compararem novilhas de descarte Charolês e Charolês x Nelore, BERNARDES et al. (2000) não observaram diferença significativa no rendimento de carcaça dos animais destas raças. 
Tabela 5 - Peso inicial, peso final, ganho de peso médio diário, condição corporal (CC) inicial, final e ganho de CC de vacas de corte de diferentes grupos genéticos

Table 5 - Initial weight, final weight, average daily weight gain, initial body condition (BC), final $B C$ and $B C$ gain of beef cows of different genetic groups

Característica

Characteristic

Grupo genético

Genetic group

\begin{tabular}{lcccc} 
& Charolês $(\mathrm{C})$ & Nelore $(\mathrm{N})$ & $3 / 4 \mathrm{C}+1 / 4 \mathrm{~N}$ & $3 / 4 \mathrm{~N}+1 / 4 \mathrm{C}$ \\
\hline $\begin{array}{l}\text { Peso inicial, } \mathrm{kg} \\
\text { Initial weight, } \mathrm{kg}\end{array}$ & $375+16$ & $331+21$ & $411+23$ & $400+22$ \\
$\begin{array}{l}\text { Peso final, } \mathrm{kg} \\
\text { Final weight, } \mathrm{kg}\end{array}$ & $471+19^{\mathrm{A}^{*}}$ & $410+20^{\mathrm{B}}$ & $520+23^{\mathrm{A}}$ & $481+22^{\mathrm{A}}$ \\
$\begin{array}{l}\text { Ganho médio diário, } \mathrm{kg} \\
\text { Average daily gain, } k \mathrm{k}\end{array}$ & $1,03+0,07^{\mathrm{B}}$ & $1,06+0,09^{\mathrm{B}}$ & $1,36+0,10^{\mathrm{A}}$ & $1,02+0,10^{\mathrm{B}}$ \\
$\begin{array}{l}\text { CC inicial, pontos } \\
\text { Initial BC, points }\end{array}$ & $2,96+0,16$ & $2,19+0,21$ & $3,09+0,23$ & $3,02+0,21$ \\
$\begin{array}{l}\text { CC final, pontos } \\
\text { Final BC, points }\end{array}$ & $4,05+0,17$ & $3,99+0,22$ & $4,08+0,23$ & $4,44+0,22$ \\
$\begin{array}{l}\text { Ganho de CC, pontos } \\
\text { BC gain, points }\end{array}$ & $1,09+0,15^{\mathrm{B}}$ & $1,81+0,20^{\mathrm{A}}$ & $0,99+0,21^{\mathrm{B}}$ & $1,42+0,20^{\mathrm{AB}}$ \\
\hline
\end{tabular}

*Médias, na linha, seguidas por diferentes letras, são diferentes $(P<0,10)$ pelo teste "t".

* Means, within a line, followed by different letters, are different $(P<.10)$ by " $t$ " test

Com relação à conformação, observa-se que esta foi superior nos animais Charolês em relação aos Nelore $x$ Charolês e Nelore. PEROBELLI et al. (1995) verificaram que a conformação de carcaça foi pior em vacas Nelore, quando comparadas a vacas Charolesas. No presente estudo, a conformação não diferiu entre as carcaças dos animais puros da raça Charolês e cruzas Charolês $\mathrm{x}$ Nelore, o que está de acordo com os resultados de BERNARDES et al. (2000), que trabalharam com fêmeas de descarte abatidas aos quatro anos de idade, desses mesmos grupos genéticos.

A cobertura de gordura sobre a carcaça foi similar entre os quatro grupos genéticos estudados, assim como as percentagens de dianteiro, costilhar e traseiro especial $(\mathrm{P}>0,10)$. Maior espessura de gordura em vacas Nelore foi verificado por PEROBELLI et al. (1995), sendo que esse grupo genético apresentou resultado superior também na percentagem de costilhar, sendo que as vacas Charolesas apresentaram maior percentagem de traseiro especial. Fazendo um estudo sobre o cruzamento rotativo das raças Charolês e Nelore, envolvendo animais de raças definidas, e suas cruzas $F_{1}$ e $F_{2}$, VAZ (1999) concluiu que a percentagem de costilhar é influenciada pela espessura de gordura sobre a carcaça. No presente trabalho observou-se que a espessura de gordura foi elevada nas vacas Charolesas $(6,14 \mathrm{~mm})$, quando comparada aos $1,54 \mathrm{~mm}$ verificados por PEROBELLI et al. (1995) em vacas dessa mesma raça.

$\mathrm{Na}$ Tabela 7, estão apresentados os resultados referentes à qualidade da carcaça das vacas dos diferentes genótipos. Pode-se verificar nessa tabela, que a percentagem de osso foi maior nas vacas Nelore em relação aos demais genótipos.

Os animais $\mathrm{CN}$ foram superiores aos $\mathrm{NC}$ na coloração da carne. CROUSE et al. (1989) concluíram que a coloração da carne piorou a medida que aumentou a percentagem de zebuíno no genótipo. No Brasil, RESTLE et al. (2000a) verificaram coloração mais clara na carne de vacas Charolês, quando comparadas com vacas Nelore e $F_{1}$ Nelore x Charolês.

Com relação à textura e o marmoreio, observa-se que estas características não foram influenciadas pelo grupo genético. Trabalhos anteriores relatam menores valores de marmoreio em carcaças de vacas (PEROBELLI et al., 1994) e de novilhos Charolês (DeROUEN et al., 1992b; VAZ, 1999), quando comparados com animais Nelore. Novamente ressalta-se que o grau de acabamento que as vacas Charolês atingiram, foi maior que o normal, portanto, pode-se dizer que a terminação em pastagem cultivada, aliada a suplementação energética é uma boa alternativa para propiciar bom acabamento de carcaça em animais de raças de maior porte, como é o caso de animais da raça Charolesa, facilitando a comercialização destes e melhorando a qualidade da carne.

Ainda na Tabela 7, pode-se verificar que a área de Longissimus dorsi foi maior nas vacas Charolesas em relação às zebuínas. A maior área de Longissimus, em parte, é devida ao maior peso de carcaça das vacas Charolesas. Entretanto, PEACOCK et al. (1979) e DeROUEN et al. (1992a) concluíram que a 
Tabela 6 - Peso de carcaça fria, rendimento de carcaça fria, conformação, espessura de gordura subcutânea, comprimento de carcaça e porcentagem dos cortes comerciais da carcaça de vacas de diferentes grupos genéticos

Table 6 - Cold carcass weight, dressing percentage, conformation, subcutaneous fat thickness, carcass length and commercial cuts of the carcass of cows from different genetic groups

Característica

\section{Grupo genético}

Characteristic

Genetic group

\begin{tabular}{|c|c|c|c|c|}
\hline & Charolês (C) & Nelore $(\mathrm{N})$ & $3 / 4 \mathrm{C}+1 / 4 \mathrm{~N}$ & $3 / 4 \mathrm{~N}+1 / 4 \mathrm{C}$ \\
\hline $\begin{array}{l}\text { Peso de carcaça fria, } \mathrm{kg} \\
\text { Cold carcass weight, } \mathrm{kg}\end{array}$ & $245,7+10,7^{\mathrm{A}^{*}}$ & $214,0+11,2^{\mathrm{B}}$ & $268,0+12,9^{\mathrm{A}}$ & $255,1+12,2^{\mathrm{A}}$ \\
\hline $\begin{array}{l}\text { Rendimento de carcaça, } \% \\
\text { Dressing percentage, } \%\end{array}$ & $52,1+0,9$ & $52,2+1,0$ & $51,4+1,1$ & $53,0+1,0$ \\
\hline $\begin{array}{l}\text { Conformação, pontos } \\
\text { Conformation, points }\end{array}$ & $10,1+0,4^{\mathrm{A}}$ & $8,0+0,5^{\mathrm{C}}$ & $9,6+0,5^{\mathrm{AB}}$ & $8,7+0,5^{\mathrm{BC}}$ \\
\hline $\begin{array}{l}\text { Espessura de gordura, mm } \\
\text { Fat thickness, mm }\end{array}$ & $6,1+1,1$ & $6,2+1,1$ & $6,6+1,3$ & $7,7+1,2$ \\
\hline $\begin{array}{l}\text { Comprimento de carcaça, } \mathrm{cm} \\
\text { Carcass length, } \mathrm{cm}\end{array}$ & $131,8+1,7^{\mathrm{A}}$ & $126,4+1,8^{\mathrm{B}}$ & $135,1+2,0^{\mathrm{A}}$ & $133,3+1,9^{\mathrm{A}}$ \\
\hline $\begin{array}{l}\text { Dianteiro, } \% \\
\text { Forequarter, } \%\end{array}$ & $36,9+0,8$ & $37,5+0,9$ & $35,6+1,0$ & $35,8+0,9$ \\
\hline $\begin{array}{l}\text { Costilhar, } \% \\
\text { Sidecut, \% }\end{array}$ & $12,4+0,4$ & $12,1+0,4$ & $12,9+0,5$ & $12,6+0,4$ \\
\hline $\begin{array}{l}\text { Traseiro especial, \% } \\
\text { Sawcut, \% }\end{array}$ & $50,7+0,8$ & $50,4+0,8$ & $51,5+1,0$ & $51,6+0,9$ \\
\hline
\end{tabular}

* Médias, na linha, seguidas por diferentes letras, são diferentes $(P<0,10)$ pelo teste " $t$ ".

* Means, within a line, followed by different letters, are different $(P<.10)$ by " $t$ " test

Tabela 7 - Características qualitativas da carcaça e área de Longissimus dorsi (LD) de vacas de corte de diferentes grupos genéticos

Table 7 - Carcass quality and Longissimus dorsi (LD) area of beef cows of different genetic groups

\begin{tabular}{|c|c|c|c|c|}
\hline \multirow[t]{2}{*}{$\begin{array}{l}\text { Característica } \\
\text { Characteristic }\end{array}$} & \multicolumn{4}{|c|}{$\begin{array}{l}\text { Grupo genético } \\
\text { Genetic group }\end{array}$} \\
\hline & Charolês (C) & Nelore $(\mathrm{N})$ & $3 / 4 \mathrm{C}+1 / 4 \mathrm{~N}$ & $3 / 4 N+1 / 4 C$ \\
\hline Osso, \% & $15,2+0,6^{\mathrm{B}^{*}}$ & $17,9+0,6^{\mathrm{A}}$ & $15,8+0,7^{\mathrm{B}}$ & $15,3+0,7^{\mathrm{B}}$ \\
\hline $\begin{array}{l}\text { Bone, \% } \\
\text { Músculo, \% } \\
\text { Muscle, \% }\end{array}$ & $62,6+1,0$ & $59,8+1,1$ & $63,1+1,2$ & $60,4+1,2$ \\
\hline $\begin{array}{l}\text { Gordura, } \% \\
\text { Fat, \% }\end{array}$ & $22,4+1,2$ & $21,6+1,2$ & $21,2+1,4$ & $24,4+1,3$ \\
\hline $\begin{array}{l}\text { Cor, pontos } \\
\text { Color, points }\end{array}$ & $4,6+0,2^{\mathrm{AB}}$ & $4,4+0,2^{\mathrm{AB}}$ & $5,0+0,2^{\mathrm{A}}$ & $4,2+0,2^{\mathrm{B}}$ \\
\hline $\begin{array}{l}\text { Textura, pontos } \\
\text { Texture, points }\end{array}$ & $2,58+0,44$ & $3,04+0,46$ & $2,93+0,53$ & $2,73+0,50$ \\
\hline $\begin{array}{l}\text { Marmoreio, pontos } \\
\text { Marbling, , points }\end{array}$ & $6,02+1,39$ & $3,35+1,46$ & $8,15+1,68$ & $4,77+1,59$ \\
\hline $\begin{array}{l}\text { Área de } \mathrm{LD}, \mathrm{cm}^{2} \\
L D \text { area, } \mathrm{cm}^{2}\end{array}$ & $66,3+2,6^{\mathrm{A}}$ & $51,4+2,8^{\mathrm{C}}$ & $64,7+3,2^{\mathrm{AB}}$ & $59,1+3,0^{\mathrm{B}}$ \\
\hline
\end{tabular}

* Médias, na linha, seguidas por diferentes letras, são diferentes $(\mathrm{P}<0,10)$ pelo teste " $\mathrm{t}$ ".

* Means, within a line, followed by different letters, are different $(P<.10)$ by "t" test. 
raça Charolês possui maior efeito genético aditivo para área de Longissimus dorsi, mesmo que essa medida seja ajustada para o peso de carcaça.

\section{Conclusões}

O uso de suplementação energética aumentou o ganho de peso médio diário de vacas mantidas em pastagem de aveia (Avena strigosa) + azevém (Lolium multiflorum).

O aumento do nível de suplementação energética melhorou o ganho de condição corporal de vacas mantidas em pastagem cultivada de estação fria.

Vacas Charolesas apresentaram melhor conformação, maior peso final, peso de carcaça e área de Longissimus dorsi do que as vacas Nelore, as quais apresentaram maior percentagem de osso na carcaça.

Entre as vacas cruzadas, as 3/4 Charolês $+1 / 4$ Nelore apresentaram maior ganho de peso médio diário durante a terminação que os demais genótipos, e, após o abate, carne de coloração mais clara que as vacas $3 / 4$ Nelore $+1 / 4$ Charolês.

A terminação de vacas Charolesas em pastagens de alta qualidade permite que se atinja maior grau de acabamento da carcaça, melhorando características que são deficientes nessa raça, como o rendimento de carcaça e o marmoreio da carne.

\section{Referências Bibliográficas}

BERG, R.T., BUTTERFIELD, R.M. 1976. New concepts of cattle growth. Sydney: Sydney University Press. 240p.

BERNARDES, R.A.L.C., RESTLE, J., VAZ, F.N. et al. Características quantitativas da carcaça de novilhas Charolês ou 3/4 Charolês $1 / 4$ Nelore, terminadas em confinamento. In: REUNIÃO ANUAL DA SOCIEDADE BRASILEIRA DE ZOOTECNIA, 37., 2000, Viçosa. Anais... Viçosa: SBZ, 2000. p.202.

CALÇA, K.G., FERREIRA, M.V.B., PASCOAL, L.L. et al. Suplementação de novilhos de sobreano mantidos em pastagem cultivada de inverno. In: JORNADA INTEGRADA DE PESQUISA EXTENSÃO E ENSINO, 3, 1996, Santa Maria. Anais... Santa Maria: UFSM, 1996. p.547.

CROUSE, J.D., CUNDIFF, L.V., KOCH, R.M. et al. 1989. Comparisons of Bos indicus and Bos taurus inheritance for carcass beef characteristics and meat palatability. J. Anim. Sci., 67(10):2661-2668.

DeROUEN, S.M., FRANKE, D.E., BIDNER, T.D. et al. 1992a. Direct and maternal genetic effects for carcass traits in beef cattle. J. Anim. Sci., 70(12):3677-3685.

DeROUEN, S.M., FRANKE, D.E., BIDNER, T.D. et al. 1992 b. Two- three-, and four-breed rotational crossbreeding of beef cattle: carcass traits. J. Anim. Sci., 70(12):3665-3676.

DI MARCO, O.N. 1994. Crecimiento y respuesta animal. Balcarce: AAPA. 129p.

FEIJÓ, G.L.D., SILVA, J.M., COSTA, F.P. et al. Produção e qualidade da carne de vacas de descarte. Desempenho em confinamento sob diferentes níveis de concentrado. In: REUNIÃO ANUAL DA SOCIEDADE BRASILEIRA DE ZOOTECNIA, 37, 2000, Viçosa. Anais... Viçosa: SBZ, 2000a. p.476.

FEIJÓ, G.L.D., SILVA, J.M., THIAGO, L.R.L.S. et al. Efeito de níveis de concentrado na engorda de bovinos confinados. Desempenho de novilhos F1 Pardo Suiço x Nelore. In: REUNIÃO ANUAL DA SOCIEDADE BRASILEIRA DE ZOOTECNIA, 33, 1996, Fortaleza. Anais... Fortaleza: SBZ, 1996a. p.73-85.

FEIJÓ, G.L.D., SILVA, J.M., THIAGO, L.R.L.S. et al. Produção e qualidade da carne de vacas de descarte. Características das carcaças de vacas em confinamento sob diferentes níveis de concentrado. In: REUNIÃO ANUAL DA SOCIEDADE BRASILEIRA DE ZOOTECNIA, 37, 2000, Viçosa. Anais... Viçosa: SBZ, 2000b. p.476.

FEIJÓ, G.L.D., THIAGO, L.R.L.S., ARRUDA, E.F. Efeito de níveis de concentrado na engorda de bovinos confinados. Características das carcaças de animais Nelore. In: REUNIÃO ANUAL DA SOCIEDADE BRASILEIRA DE ZOOTECNIA, 33., 1996, Fortaleza. Anais... Fortaleza: SBZ, 1996b. p.76-78.

FEIJÓ, G.L.D., THIAGO, L.R.L.S., JOBÁ, I. Efeito de níveis de concentrado na engorda de bovinos confinados. Características das carcaças de animais F1 Pardo Suiço / Nelore. In: REUNIÃO ANUAL DA SOCIEDADE BRASILEIRA DE ZOOTECNIA, 33., 1996, Fortaleza. Anais... Fortaleza: SBZ, 1996c. p.79-81.

GALVÃO, J.G., FONTES, C.A.A., PIRES, C.C. 1991. Características e composição física da carcaça de bovinos não-castrados, abatidos em três estágios de maturidade (Estudo II) de três grupos raciais. R. Soc. Bras. Zootec., 20(5):503-512.

HANKINS, O.G., HOWE, P.E. 1946. Estimation of the composition of beef carcasses and cuts. Washington: United States Department of Agriculture (Technical Bulletin, 926).

MÉNDEZ, D.G., DAVIES, P., DILLON, A. 1997. Utilizacion de grano de maiz y sorgo, y de um concentrado protéico como suplementos de un verdeo invernal. Rev. Arg. Prod. Anim., 17(Sup.1):7.

MOTT, G.O., LUCAS, H.L. The design conduction and interpretation of grazing trials on cultivated and improved pastures. In: INTERNATIONAL GRASSLAND CONGRESS, 6., 1952, Pensylvania, Proceedings... Pensylvania: State College Press, 1952, p.1380-1395.

MULLER, L. 1987. Normas para avaliação de carcaças e concurso de carcaça de novilhos. 2.ed. Santa Maria: Imprensa Universitária. 31p.

PASCOAL, L.L., RESTLE, J., ROSO, C. 1999. Desempenho e economicidade da suplementação em pastagem. In: RESTLE, J. (Ed.) Confinamento, pastagens e suplementação para produção de bovinos de corte. Santa Maria: UFSM. p.62-84.

PEACOCK, F.M., PALMER, AZ., CARPENTER, J.W. et al. 1979. Breed and heterosis effects on carcass characteristics of Angus, Brahman, Charolais and crossbred steers. J. Anim. Sci., 49(2):391-397.

PEROBELLI, Z.V., MULLER, L., RESTLE, J. 1994. Estudo da qualidade das carcaças e da carne de vacas de descarte de dois grupos genéticos. Ciência Rural, 24(3):613-616.

PEROBELLI, Z.V., RESTLE, J., MULLER, L. 1995. Estudo das carcaças de vacas de descarte das raças Charolês e Nelore. Pesq. Agropec. Bras., 30(3):409-412.

PRICE, J.F., SCHWEIGERT, B.S. 1994. Ciencia de la carne y de los productos carnicos. 2.ed., Zaragoza: Editorial Acribia. 581p. 
RESTLE, J., BERNARDES, R.A.L.C., ALVES FILHO, D.C. et al. Efeito de grupo genético e heterose na qualidade da carne de vacas terminadas em confinamento. In: REUNIÃO ANUAL DA SOCIEDADE BRASILEIRA DE ZOOTECNIA, 37 , 2000, Viçosa. Anais... Viçosa: SBZ, 2000a. p.215

RESTLE, J., EIFERT, E.C., BERNARDES, R.A.L.C. et al. Características de carcaça de novilhos terminados com diferentes fontes de volumoso. In: REUNIÃO ANUAL DA SOCIEDADE BRASILEIRA DE ZOOTECNIA, 37, 2000, Viçosa. Anais... Viçosa: SBZ, 2000b. p.356.

RESTLE, J., EIFERT, E.C., PASCOAL, L.L. et al. Altura de corte da silagem e dos níveis de concentrado na produção de terneiros para abate aos 12 meses de idade. 1 - Características da carne. In: REUNIÃO ANUAL DA SOCIEDADE BRASILEIRA DE ZOOTECNIA, 37, 2000, Viçosa. Anais... Viçosa: SBZ, 2000c. p.331.

RESTLE, J., LUPATINI, G.C., ROSO, C. et al. 1998a. Eficiência e desempenho de categorias de bovinos de corte em pastagem cultivada. Rev. bras. zootec., 27(2):397-404.

RESTle, J., ROSO, C., OLIVEIRA, A.N. et al. 2000 d. Suplementação energética para vacas de descarte de diferentes idades em terminação em pastagem cultivada de estação fria sob pastejo horário. Rev. bras. zootec., 29(4):1216-1222.

RESTLE, J., VAZ, F.N., ALVES FILHO, D.C. et al. Aspectos quantitativos da carcaça de vacas de descarte, terminadas com diferentes níveis de concentrado. In: REUNIÃO ANUAL DA SOCIEDADE BRASILEIRA DE ZOOTECNIA, 35, 1998, Botucatu. Anais... Brasília: SBZ, 1998b. v.1, p.140-142.

RESTLE, J., VAZ, F.N., BRONDANI, I.L. et al. Características de carcaça de vacas, terminadas com diferentes níveis de suplementação em pastagem cultivada de estação fria, sob pastejo horário. In: REUNIÃO ANUAL DA SOCIEDADE BRASILEIRA DE ZOOTECNIA, 37, 2000, Viçosa. Anais... Viçosa: SBZ, 2000e. p.354.
ROMANS, J.R., ZIEGLER, P.T. 1977. The meat we eat. 11.ed. Danville: Interstate Printers and Publishers Inc. 780p.

ROSO, C. Produção animal em misturas de gramíneas anuais de estação fria. Santa Maria: UFSM, 1998. 104p. Dissertação (Mestrado em Zootecnia) - Universidade Federal de Santa Maria, 1998.

ROSO, C., RESTLE, J. 2000. Aveia preta, triticale e centeio em mistura com azevém. 2. Produtividade animal e retorno econômico. Rev. bras. zootec., 29(1):85-93.

ROSO, C., RESTLE, J., SOARES, A.B. et al. 2000. Aveia preta, triticale e centeio em mistura com azevém. 1. Dinâmica, produção e qualidade de forragem. Rev. bras. zootec., 29(1):75-84.

SAS, Institute Inc. 1990. SAS language reference. Version 6, Cary, NC: SAS Institute Inc. 1042p.

SCHNELL, T.D., BELK, K.E., TATUM, J.D. et al. 1997. Performance, carcass and palatability traits for cull cows fed with high-energy concentrate diets for $0,14,28,42$ or 56 days. J. Anim. Sci., 75(5):1195-1202.

VAZ, F.N. Cruzamento alternado das raças Charolês e Nelore: características de carcaça e da carne de novilhos abatidos aos dois anos. Santa Maria, RS: UFSM, 1999, 58p. Dissertação (Mestrado em Zootecnia) - Universidade Federal de Santa Maria, 1999.

Recebido em: 22/01/01

Aceito em: 13/06/01 